observations 1813 to 1882 . In selecting the years, those only have been chosen in which the aggregate fall of rain has been at least 20 per cent. less than the average. The table further gives the total fall and difference from the average for the first ten months in each of these years, and in the last column will be found the number of months during which the rainfall has been deficient.

From the first two columns it appears that the years I 858 and I 864 claim the distinction of being the driest of all, the total falls being only 17.3 inches and 17.4 inches respectively, or 30 per cent. less than the average. Next comes 1847 , with a total fall of $17 \%$ inches and a deficit amounting to 29 per cent. As regards the period of ten months, the present year has been drier than any of the past seventy-one, but in the year 1847 the rainfall was nearly as deficient. In the case of the other dry years the aggregate fall for the ten months was at least an inch more than in either I 847 or I 884 , and in the years I 832 and I\$37 it was three inches more. On comparing the returns for the past seventy-one years, one more striking fact is brought to light. Out of the whole series there has been only one occasion on which the deficiency of rain has continued through a greater number of months than it has this year. This long period of drought commenced in November 1846 and continued until November 1847 , and there were consequently no fewer than thirtecn consecutive months during which the rainfall in London was below the average.

FREDK. J. BRODIE

\section{ANCIENT CHINESE GEOGRAPHY}

NOT long since the Chinese Ambassador to England, in the course of a remarkable speech at Folkestone, twitted European scholars with the labours which they freely bestowed on the study of extinct nations and races, while the still existing civilisation of China, hardly inferior in antiquity to that of any other race, received but scant attention. Whether the charge is well founded or not we cannot pretend to decide here; but there is, we believe, no doubt that there is still in Chinese literature a vast mine, into which but few and trifling shafts have been sunk. The wealth of the geographical literature of China, for instance, is known to but a few scholars, and one of these, M. de Rosny of Paris, in a work recently published on the Oriental nations known to the ancient Chinese, says that, among all the literatures of the East, that of the Chinese probably contains the most valuable information for the study of Asiatic ethnography, for a crowd of nations which have disappeared, or which are unknown in Europe, have been the subject of substantial notices by the Chinese, outside which, probably, we know nothing of their political history or of the annals of their civilisation. M. de Rosny's work, which is published by the Ethnographical Society of Paris, is devoted to the translation and piecing together of extracts from old topographical works respecting various countries known to the Chinese in ancient times. Much of the labour in a work of this kind must necessarily be devoted to identifying the places mentioned. In many cases this has not even now been satisfactorily dure. Thus, the uigin of the name Ta-tsin, applied to the Roman Empire, is wrapped in obscurity. The latest theory is that it is the phonelical representation of Tarsus in Cilicia, whence Antoninus sent ambassadors to Bactria, so that the name of Tarsus was the first echo which China received of Rome. But although there is much in M. de Rosny's volume which can only interest the technical Sinologue, yet one can gather from the text, as well as from the maps, a fairly accurate idea of the knowledge of geography possessed by the Chinese in early times. Of the maps, which are nine in number, one contains the Indian Archipelago as known to the Chinese, and six others Indo-China and Malaysia, according to Chinese geographers, at various periods from the twelfth century before our era down to 906 after Christ.
The Chinese, then, according to M. de Rosny, have from the most remote times occupied themselves with the topography of the districts through which they migrated, and have studied the geography of the neighbouring countries. Yu the Great, who reigned in the basin of the Yellow River twenty-two centuries before our era, was a veritable geographer. The Shu-king, which contains an account of the public works executed under his direction, contains the first rudiments of Chinese ethnigraphy, as Genesis does that of the Jews. A geographical work which is probably not less ancient is the Shau-hai-king. It is at least as old as the Choo dynasty-Ir34 B.C.- -and some Chinese authors even carry its date back to the twenty-seventh century before Christ. In a book of rites of the Choo dynasty just referred to, it is stated that twenty-four officials were specially charged with the administration of a department for national geography. It is, however, to the historians that we have to look for accounts of the various peoples which early submitted to the preponderating influence of the Middle Kingdom. The nomad hordes of the north and west, and the States then in process of formation in the south, all entered into relations with the Chinese. The ambassadors whom they sent to the Court brought with them information as to the people they represented, which was duly consigned to the archives of the Empire by its historiographers. The officials sent by the Chinese in return to the peoples about them contributed their quota of geographical and ethnographical facts, until ultimately the documents on the subject became so numerous that native scholars judged it well to summarise them into one great work. It was thus that the great encyclopædia associated with the name of Ma-touan-lin was formed. Its first publication was in 1322 .

The limits of the world as known to the early Chinese are stated by M. de Rosny to be: in the north, Southern Siberia and Kamchatka; in the east, the Kurile Islands, Japan, the Loochoo Archipelago, and that of the Philippines; in the south-east, Borneo and Celebes; to the south, Java, Sumatra, and Ceylon; to the west, Arabia, Persia, and the States bordering on the Caspian. Some scholars have professed to discover the Roman Empire under the name Ta-tsin, and America, which a mission of Shamans are said to have discovered in the fifth century, under that of Fousang. In the work before us the writer gives, from Ma-touan-lin and other sources, the statements of the early Chinese writers with regard to the various races inhabiting these regions; but he warns us more than once that these ancient documents, though of great value in teaching us about peoples little known to us, must be used with the utmost reserve, and only after undergoing a searching examination and criticism. The present instalment of the work deals only with the races to the south, south-east, and east, such as the Japanese, Ainos, Siamese, \&c. Its value as an ethnographical and geographical work can only be known to the one or two living Europeans who have made a special study of the subject; but it places beyond doubt the fact that students of the ethnography and historical geography of the Far East will have to reckon with the works of their remote Chinese predecessors before their knowledge can be regarded as complete.

\section{COLOUR}

M M. A. ROSENSTIEHL has made an interestN. ing contribution to the science of colour in the form of a brochure recently published under the auspices of the Société Industrielle of Rouen, and entitled "Les premiers Eléments de la Science de la Couleur." In this treatise, which is a model of brevity and of demonstrative clearness, the author shows that the empirical methods which have hitherto prevailed amongst colourists of all classes are radically imperfect. These methods are 
based entirely upon the study of colouring matters, and ignore altogether the fundamental distinction between colour as a property of such matter, and colour in the physiological sense of a particular affection of the organ of sight. It is to the study of colour by means of coloursensations that our attention is directed; and it is to the synthesis and analysis of the retinal impressions that we are to look for exact views on the relationships of the colours. The distinction in question once stated is so obvious that the author's claim for recognition of the new system or method as the necessary complement of the older will be at once admitted. But the author's aim is not so much to obtain the intellectual assent of those accustomed to the propositions of abstract science, as rather to convince colour-artists of every denomination of the direct utility of the method-to show them, in fact, that it supplies the means of solving problems in colouring with rapidity and certainty, and furnishes valuable criteria with which to strengthen the asthetic judgment.

The chief obstacles to the general acceptance of the method lie in the erroneous views which underlie the well-worn proverb, "Il ne faut pas disputer des gouts et des couleurs." While, in opposition to these tenets, the author contends for the admission of more positive views, and of the experimental method upon which they are based, he very distinctly disclaims the idea of substituting taste and artistic inspiration by a set of mathematical rules. "Taste," he says, "must ever remain the supreme judge of the resthetic value of any combination of colours."

It is true that the artistic instinct confers upon its possessor a comparative independence of the methodical selection of colour; but this instinct, or intuitive perception of harmony, is by no means an unerring guide, nor without the influence of prevailing ideas. Most of these are of necessity incomplete, and many are demonstrably false : and the artistic instinct therefore needs development and correction. In the abstract which we shall give of the author's treatise, we shall give due prominence to the evidences of these shortcomings.

The elaboration of the empirical system still prevalent we owe to Chevreul. It is based entirely upon the study of colouring-matters, and its scales of colour-relationships are purely arbitrary. The theoretical treatment of colour, on the other hand, has been chiefly, and indeed necessarily, confined to the investigations of the spectrum. Early in this century, Young, the father of our modern science of light, formulated a theory of colour-sensation, a theory, that is to say, which co-ordinated the physical phenomena of coloured light with the phenomena of its appreciation by the eye. Colour, we know, is the expression of wave-length; the sense of colour was referred by Young to the agency of distinctive retinal nerves, each endowed with the capacity of selective excitation by rays of certain wave-lengths. He recognised, further, three primary divisions of wave-lengths, corresponding to red, blue, and yellow light. The later researches of Maxwell have given results confirmatory of this view, and additional testimony to the wonderful insight of this great philosopher. But we are not concerned at this moment with the theories and speculations of pure science so much as with the more practical question of the advantage to the colourist of correcting impressions derived from the empirical study of pigments, by the study of colour in the light of their main results and consequences. A very praiseworthy effort to bridge over the gap which had so long existed between the science and the art of colouring has been made by Prof. von Bezold in the publication of his work on the "Science of Colour." This excellent treatise, in spite of its translation into English, has, we think, not received the attention in this country which it deserves; this is accounted for in part by its publication in America, but an equally powerful cause is to be found in the conservatism of those to whom it appeals, in the jealousy of invasion by the forces of a new method of a territory rendered sacred by inheritance.

In both treatises considerable importance is attached to the reduction of the various terms in conventional use to the accurate expression of the ideas involved in the scientific investigation of colour. This is a task of considerable difficulty.

M. Rosenstiehl finds the French terms especially difficult to handle. The three principal substantive;, muance, teinte, and ton, he assigns - though with a confession that his choice is somewhat arbitrary-to the three variables respectively which determine a colour, viz. kind or quality (espèce), intensity, and purity. In this choice he admits that the terms ton and nuance may be said to have an inverse relationship to that which they occupy in musical language, but at the same time justifies the selection as most in accordance with present usage, pointing out, moreover, that the analogy between the ear and the eye is so slender that it is not to be sought in the terms which express their sensation;. The translator of Bezold finds himself called upon to accommodate himself in his treatment of the subject to the use of the terms hue, tint, shade. To avoid prolixity we give as the result of a careful consideration of the terminology of both authors the following definitions of essential terms :-

(I) Colour in the sense of wave-length must be denominated by hue.

(2) The degree of brightness (French, intensité) we may express by tint.

(3) The degree of purity, i.e. non-admixture with white, may be rendered by tone.

It is obvious that (2) and (3) are, in regard to the ordinary conditions of vision, interdependent variables, for, as the intensity or illumination increases, the proportion of white increases.

It will be found on trial that, by means of these three substantives, the essential factors of any colour may be expressed. It is clear that habit will prevent our specialising the use of the word colour; but we may limit its use scientifically to the general expression of primary distinctions, reserving the term hue to indicate specially wave-length and variations in wave-length. There still remains, however, the important word shade to dispose of, amongst the substantives in conventional use, as well as the numerous adjectives with which they have been conjoined.

The more general use of shade has been to express the idea contained in (3), i.e. the toning of colours by addition or removal of white, and this use may be retained. At the same time, in order that our nomenclature may be precise, we must obviously avoid such expressions as a "red shade of orange, using instead "red-orange hue," or even "red hue of orange," or again, "dark shade of green," meaning thereby a green of medium tone perhaps, but of low illumination; the correct expression here would be "a green, a dark or low tint" (couleur foncée).

The term couleur saturée is applied by M. Rosenstiehl to a pure colour, or the corresponding visual sensation : such colours are obviously never met with in the arts; those which approximate to saturation he terms couleurs franches. These adjectives are perhaps best translated by integral and full respectively.

The spectral hues are integral; full colours or tones are those which give the impression of quantity of colour.

The term gamut or scale is used in two senses: first, to indicate a graduated succession of tones, i.e. the gradations of a given hue through its several tones to white ; and second, a graduated succession of tints, or the gradations of a given hue through its several tints to black.

The asthetic gamut or scale is the term applied by the author to graduated modifications of one and the same colour-sensation; its special significance will become 

more apparent as we proceed in our examination of $\mathrm{M}$.
Rosenstiehl's work.

For the investigation of colours, or rather of colouringmatters, the author employs concentric disks, which are kept in rapid rotation by mechanical means of the simplest character. These disks may be coloured uniformly or in sectors of various hues; the well-known result of the rapid rotation is in the latter case the mixture of the sensations
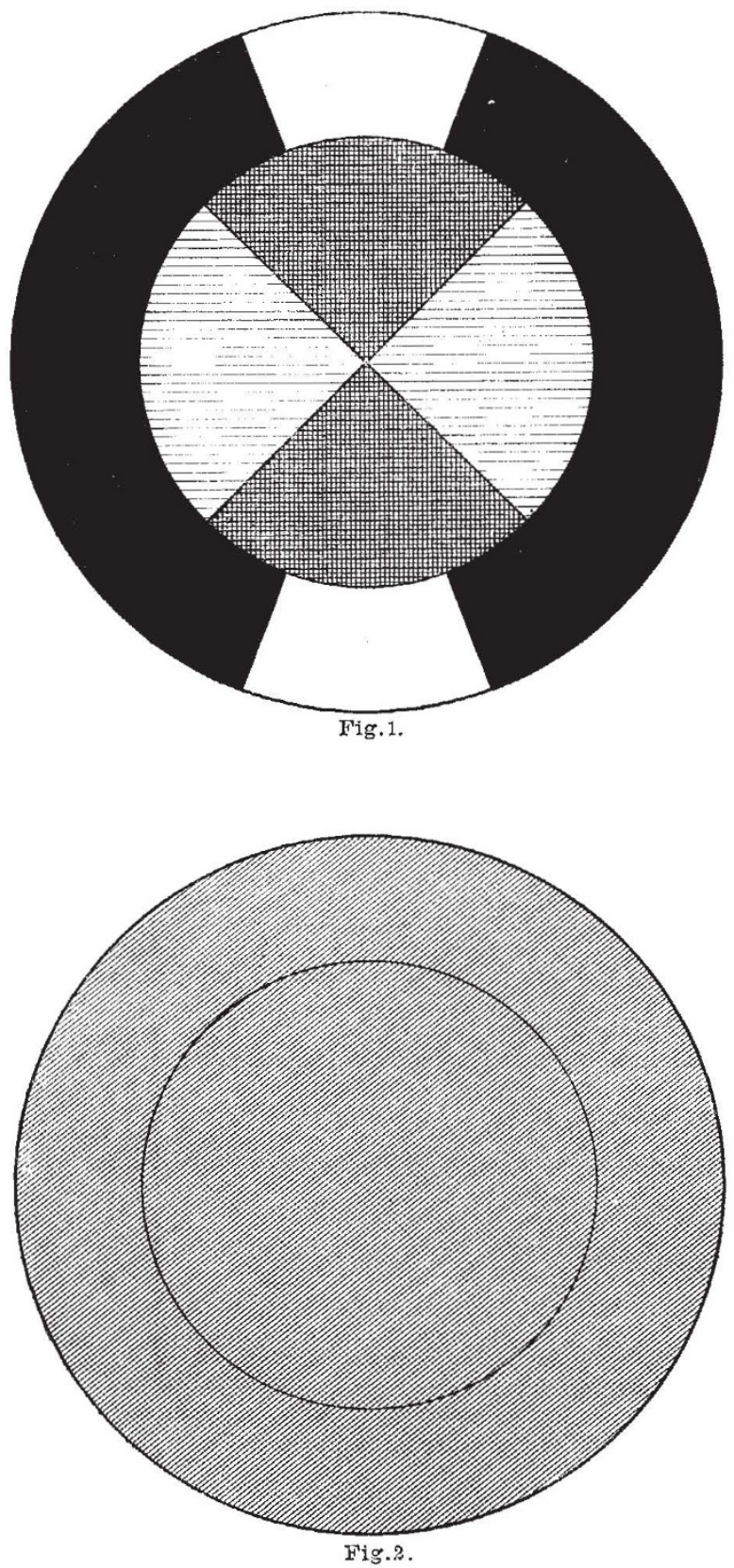

of light, then fusion into a single uniform coloured impression. In the study of the degradation of colours by admixture, it is necessary to have both a black and a white. The white is obtained by means of precipitated barium sulphate applied to a suitable surface; the black is obtained by means of a small chamber before which the disks rotate, this chamber being lined with black velvet. The admixture of black is then produced by cutting from the disk a sector; the disk being then placed before this chamber adds the sensation of black to that of colour in the proportion of the size of the sector removed to that of the disk. A special apparatus is described for measuring the sectors of the disks, as is also the very necessary instrument by which the disks are cut with or without the simultaneous removal of sectors.

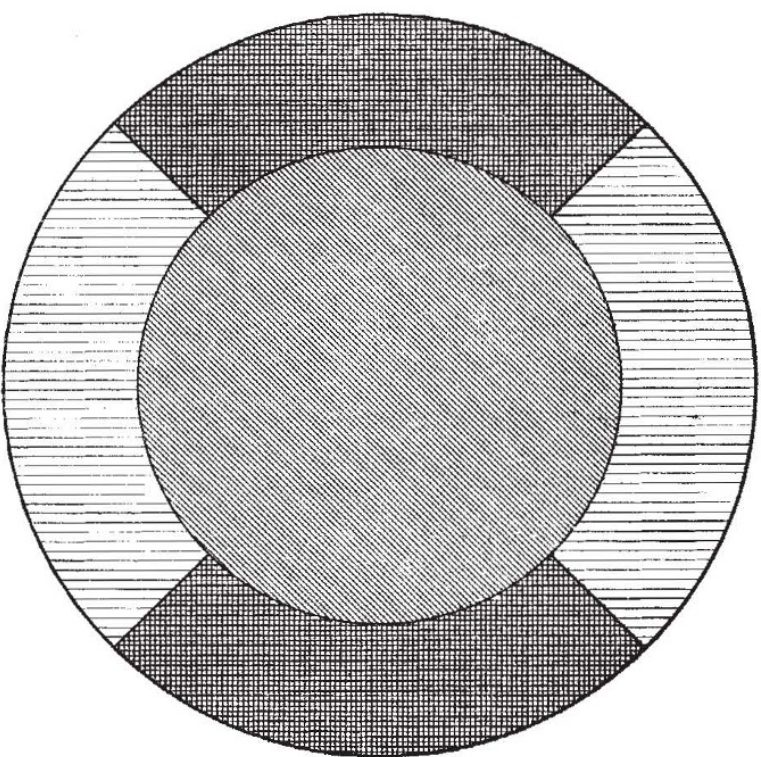

Fig.3.

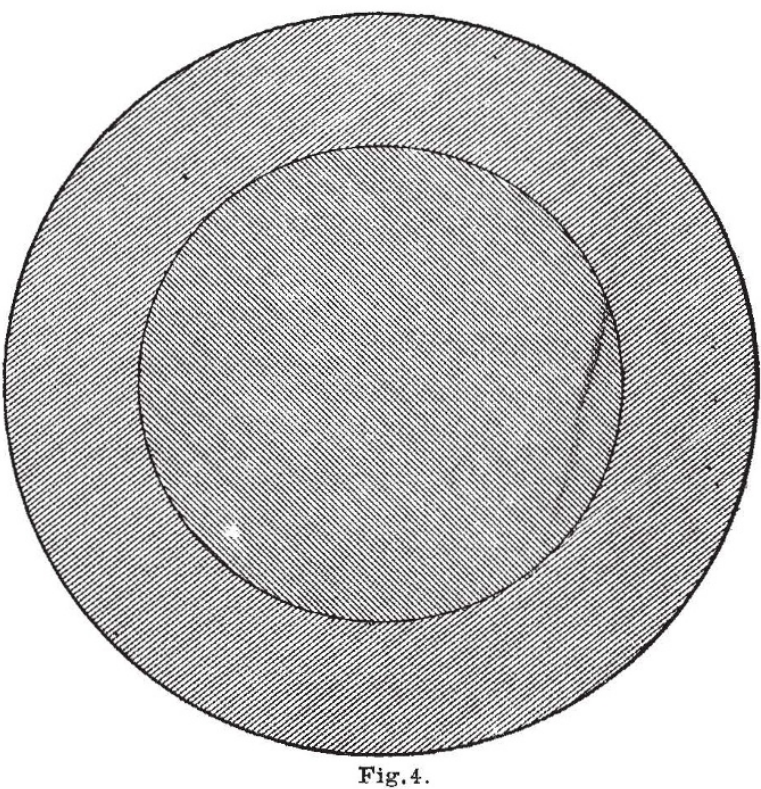

The author's experimental results are given in a series of coloured plates, to which descriptive notes and expla. nations are attached. Some of these we proceed to reproduce. Plate $I$ in the book is a study of complementary colours or hues. The superposed disks are represented both at rest (Fig. I) and in motion (Fig. 2); the mechanical details, such as the attachment of the disks to the re- 
volving axis, are suppressed for the sake of clearness. Under the condition of rapid rotation both disks appear to be coloured a uniform grey.

Thus in a single experiment is demonstrated (I) that blue and yellow are complementary colours, (2) that particular tones of blue and yellow produce by mixture of retinal impressions a white of low tint-in fact, by measuring the sectors composing the outer annulus, a white of 2-9ths the intensity of that of the annulus, which is produced by barium sulphate. Other binary combinations will be found to produce similar results, e.g. red and blue-green, violet and ycllow-green. In fact given any hue, a second may be formed by means of this apparatus, such that the combination of the retinal impressions proper to each shall produce the sensation of white, the degree of this sensation varying with the tone of the constituents of the combination.

From the experimental investigation of complementary hues the definition of intensity is readily deduced. In the sectors of the plate we notice equality of area. $\mathrm{Had}$ we taken a fuller yellow of the same hue, the grey produced with the blue sector of equal area would have shown a yellow cast, and to restore the neutral grey or low white we must increase the area of the blue at the expense of the yellow. The relative intensity of complementary hues is thus defined to be the reverse of the sectors necessary to produce neutrality of hue.

The use of the particular yellow pigment of Fig. I, coloured in the original chromate of lead, is dictated by the lowness of tints of all our blue pigments; the purest of our ultramarines, smalts, and aniline blues do not possess one-third the intensity of chromate of lead; and the same is true of the greens and violets.

The study of complementary colours leads directly to the discussion of the basis of this phenomenon, whether, i.e. it is physical or physiological? It is in this department of the subject that confusion of ideas has longest persisted. Although it was pointed out by M. Plateau as long ago as 1829 that the mixture of colouring-matters and of colour-sensations are distinct phenomena, the classical experiment of Muschenbroek, dating from 1762 , is still retained by lecturers and text-books, together with erroneous interpretations. Newton himself fell into the same error in his discussion of the recombination of the spectral colours. The author puts the matter in the clearest light by pointing out that there are a number of mixtures producing the sensation of white light, - that psychological identity, therefore, is no criterion of physical identity.

The distinction is perhaps most clearly demonstrated by a plate of figures representing the superposed disks at rest and in motion. The outer annulus is composed of alternate and equal sectors of blue and yellow, the inner disk being coloured with a mixture of blue and yellow pigments in equal proportions. The distinction in appearance produced by motion affords the clearest demonstration of the point in question (Figs. 3 and 4).

The next portion of the treatise is devoted to the study of mixtures of colours, i.e. colour-sensations, which are not complementary. The more important results are those obtained in the so-called "degradation" of pigments. Such pigments, for instance, when applied to a white surface, will be more or less mixed with white, i.e. the sensations of white will be more or less conjoined with that of the pigment hue, as the quantity of pigment per unit of surface is less. The author reproduces series of such tones, in the case of Prussian blue and chrome yellow, together with their respective complementaries. In both cases it is found that the progression is accompanied by an alteration in hue, the fuller tones being distinctly redder. It is clear, therefore, that to construct a scale or gamut of tones with any given pigment, in order that this shall have an æsthetic or standard value, each tone must be referred to the same complementary, and the tones due to the pigment alone will need correction in accordance with their demonstrated imperfections, i.e. departures from the standards determined by the method of physiological comparison.

The author has very carefully compared such scales of tones with the purely arbitrary scales of M. Chevreul, and has found the differences to be considerable. Such indeed might be inferred indirectly from M. Chevreul's definition of "the tones of a colour"; they are, according to him, "the different degrees of intensity of which a colour is susceptible according as the substance by which it is produced (représenté) is pure or mixed with white."

A comparison of colour combinations harmonised according to the two systems, will show the æsthetic superiority of the physiological method, judged, that is, by the much abused arbiter, taste. It is unnecessary further to insist upon the practical importance of such conclusions. It will doubtless have been already appreciated on the part of the reader that the confusion of ideas which it is the object of this treatise to eliminate cannot have remained without influence upon the education of the eye ; nor can he fail to see that the training involved in the practice of the author's experimental method is a valuable esthetic discipline, as well as a precise study of colour relationships.

We have attempted to give an idea of the difference in appearance of the disks by lines on a white surface.

\section{THE LATE FERDINAND VON HUCHSTETTER}

THE numerous friends and admirers of the late Dr. Ferdinand von Hochstetter in Europe and Australasia have to thank his old associate, Dr. Julius von Haast, for a graceful tribute paid to his memory, which takes the form of a sympathetic biographical notice published towards the end of last August at Christchurch, New Zealand. The memoir, which is accompanied by two portraits, from a lithograph and a photograph showing the distinguished naturalist in his twenty-ninth and fiftieth years respectively, is taken for his early career partly from an account in Brockhaus's "Conversations Lexicon," and for the period since the two friends first met at Auckland, N.Z., in I 858, from Hochstetter's writings and private correspondence. Born on April 30, 1829, at Esslingen, Wurtemberg, the future naturalist was at first intended for the Church by his father, Prof. Christian Ferdinand Hochstetter, chief pastor of that town, and himself a botanist of no mean repute. But in the seminary of Maulbronn near Tübingen, his love of science, implanted in the paternal home, grew so strong that, besides theology, he afplied himself with great zeal to the study of mineralogy, palæontology, and geology. After taking his degree of Doctor Philosophiæ in 1852 he seems to have finally made choice of a scientific career, and in 1853 found employment on the Geological Survey of the Austrian Empire, soon after receiving the appointment of Chief Geologist for the Bohemian Section. His reports on the geology of the Boehmer. Wald were so highly appreciated that he was selected in 1857 as geologist of the Novara Expedition, which brought him to Auckland on December 22, 1858. Here his services were at once secured by the Government, and with the reluctant consent of the Commodore of the Novara he accepted an engagement of eight months to examine the geology, physical features, and natural history of New Zealand. During this period he made extensive topographical and geological surveys of the provinces of Auckland and Nelson, the results of which were embodied in his standard work, "Neu Seeland," published in 1863, followed in 1867 by the greatly enlarged English edition dedicated to the Queen. Soon after his return to Europe he was appointed Professor of Geology and Mineralogy in the Technical University of Vienna, and after a visit of some months to England in 1860 he settled permanently in the Austrian capital, where, in April I86I, he married 